\title{
Stereotypes and Prejudices in Communication between Chinese Ethnic and Indigenous Moslem in Medan City, North Sumatra Province - Indonesia
}

\author{
Suwardi Lubis ${ }^{1}$, Riza Buana ${ }^{2}$ \\ 1,2Faculty of Social and Political Sciences, Universitas Sumatera Utara, Indonesia \\ Email: lubis.suwardi@yahoo.co.id
}

\begin{abstract}
:
There are still elements of stereotypes and prejudices, which cause social distance and become obstacles to the harmonization of relations between indigenous Moslem and Chinese ethnic in Medan city. Stereotypes are characterized by a variety of labels from each ethnic group, namely: Like to group; strong family ties; rude and arrogant; aggressive and ignorant of customs; like to steal; cunning and breaking promises; poorly educated; tenacious and likes to work hard; ethnic prejudice is expressed in various forms, namely: anti-residence; avoidance; discrimination; Intercultural communication between them which ultimately did not take place effectively, where each ethnic group still retains its ethnic identity and does not want to understand the culture of other ethnic groups. The communication that is intertwined ultimately is only pseudo, rigid and shallow. Stereotypes and prejudices are the main obstacles that cause among other things the existence of social distance and the difficulty of assimilation that inhibits the integration of society in the city of Medan and the Indonesian nation as a whole.
\end{abstract}

\section{Keywords:}

stereotypes; prejudices; intercultural communication; indigenous moslem; chinese ethnic

\section{Introduction}

Indonesian society consists of various ethnic groups, so it is called a plural society. Pluralism is certainly a positive value because with diversity, components of Indonesian society can gather and develop various national potentials. Various cultures in Indonesia are extraordinary wealth. But on the other hand the diversity of traditions and religions is easy to cause friction between various ethnic groups. With the diversity of ethnicities and cultures that exist, it has the potential to cause problems in intercultural communication. Differences in values, norms and perceptions of each ethnic group in the form of stereotypes and prejudices often lead to misunderstandings in communication (Spencer-Rodgers and McGovern 2002).

Communication between humans is bound by culture, different cultures from one another cause the practice and behavior of communication individuals who are built in society will also be different (Ting-Toomey 1984)(Ogbu 1992)(Bandura 2001). It can be said that it is through cultural influence that humans learn to communicate and view their world through categories, concepts and symbols. Besides that, it was impressed that each person from a different culture had different views in positioning an object or situation, and vice versa.

Communication is one part of the relationship between humans both individuals and groups in everyday life1, from this understanding is clear that communication involves a number of people where one expresses something to other people, so who is involved in communication is the man himself. (Batubara, 2019). 
The misunderstanding between ethnic groups is partly due to differences in perception and behavior in the form of stereotypes and prejudices (Ting-Toomey 1984)(Guyll et al. 2010). Stereotypes and prejudices that occur among communication actors can disrupt intercultural understanding and create barriers to communication and interaction. Remembering that stereotypes and prejudices are not something that comes naturally, but are learned, both from people with whom interactions are often carried out, as well as from personal experiences as well as from the mass media (Mannix and Neale 2005)(Neuner and Karwacka-Vögele 2012).

Stereotype is the giving of certain attributes, labels, or stigma to certain groups or groups. Stereotypes that justify an ethnicity need to be investigated for the truth, whether these stereotypes are indeed true, so it needs to be thought about how to interact properly in accordance with their character (Jost and Banaji 1994)(Hilton and Hippel 1996)(Kunda and Spencer 2003).

In Indonesia, Chinese ethnic as a minority group are often the target of racial prejudice, although legally they have become Indonesian citizens. Vice versa, ethnic Chinese often have prejudices against indigenous Moslem. A prejudiced attitude is clearly unfair, if the attitude taken is only based on experience or what is heard.

Interaction between indigenous Moslem and Chinese ethnic is limited due to stereotypes. Indigenous Moslem has their own stereotypes of Chinese ethnic, and vice versa. The influence of stereotypes on individuals will have a very large prejudice in social interaction, so that it can change the behavior of individuals against other individuals who are subjected to stereotypes (PG 1989) (Fiske 1993) (Greenwald and Banaji 1995).

\section{Research Methods}

The research method used in this study is qualitative research. While this type of research uses a descriptive approach, in which the researcherdescribe in-depth questions on the subject of research. In this research is not only limited to data collection, but includes analysis and interpretation of data that has been collected and everything in this research is determined from the results of data collection that reflects the real situation on the ground. Qualitative research can be defined as research conducted in certain settings that exist in real life with the intention of investigating and understand the phenomenon; what happened and how it happened. This study aims to understand a phenomenon in a social context naturally by prioritizing the process of deep communication interactions between researchers with the phenomenon under study.

The location of the research will be conducted at SMA Negeri 1 Pantai Cermin serdang bedagai sufficiently allows the writer to conducting research. The data collection techniques used in this study are by using the In-depth Interview technique. An interview is a conversation between researchers is a person who hopes to get information, and the informant is a person who is assumed to have important information about an object of research. 


\section{Result and Disscussion}

\subsection{Results}

\section{a. Interaction between Indigenous Moslem and Chinese Ethnic}

Interaction between indigenous Moslem and Chinese ethnic in Medan is still characterized by stereotypes and prejudices. Pseudo-harmonious relations become a hidden problem between the two ethnic groups. If a problem occurs, whether sourced from Chinese ethnic or not, then Chinese are always the target. Several factors cause social distance between indigenous Moslem and Chinese ethnic, among others, first, there is no change in Chinese ethnic culture patterns into the local population, namely indigenous Moslem, or the strong ingroup feeling of Chinese ethnic towards their culture. Second, the assumption of Chinese ethnic culture is higher than indigenous Moslem. Third, stereotypes and negative prejudices against indigenous Moslem such as: lazy, stupid, and cannot use good opportunities. Preferably, the stereotypes of indigenous Moslem towards the Chinese also emerge, such as the Chinese ethnic who are stingy, cheating, cunning, and others. Chinese ethnic stereotypes and prejudices that occur in Medan City have almost the same root of the problem in several other areas in North Sumatra and even in Indonesia. So what happens is Prejudice activates stereotypes and stereotypes reinforce prejudice. Hygiene affect the incidence of skin diseases because personal hygiene greatly determines health status, where individuals consciously and on personal initiative maintain health and prevent disease. In addition, scabies is closely related to individual behavior that does not support clean and healthy living behavior (Jasmine, 2016).

Prejudice as an (usually negative) attitude towards certain group members, all based on their membership in the group (Baron and Byrne 1987). Prejudice is a phenomenon that can only be found in social life (Pettigrew 1997)(Crandall, Eshleman, and O’Brien 2002). One may not be prejudiced if he has never experienced social contact with another individual. Prejudice has a heuristic function (shortcut), which is to directly assess something without processing it in detail in our mind (cognition) (Bodenhausen, Kramer, and Siisser 1994)(Epstein 1994). The point is that we don't always waste time and energy on something that we know in advance.

The problem is that there is so much prejudice that the resulting judgments are irrational and ultimately make wrong decisions. Stereotypes are generalizations about groups of people that greatly simplify reality, whereas prejudice is a rigid attitude towards a group based on false preconceptions. Prejudice can also be understood as an assessment that is not based on knowledge or testing of available information (PG 1989).

The results showed that stereotypes and prejudices based on ethnic sentiment were built by structural conditions with the dominance of Chinese ethnic in the field of trade, which were not rivaled by indigenous Moslem in Medan. Meanwhile, indigenous Moslem dominates the political field, which is strategic for social policy. It is undeniable that these stereotypes and prejudices are formed based on the experience of interactions with other individuals or certain groups of individuals. The Chinese ethnic experience received certain treatment from indigenous Moslem so strongly shaped their stereotypes and prejudices, and vice versa.

Ability will form a special idea about a particular culture to understand the cultural background, in the context of communication, there are several factors that need to be understood, namely the mindset of each individual, stereotypes, emotions, traditions, values, norms, and religious systems (Geertz 1973). The above facts show that in communicating, each ethnic member will be guided by the norms, rules, and ethnic culture. In communication between Chinese ethnic and indigenous Moslem, there are various innate values, norms, rules, traditions and culture that serve as guidelines for communicating by each ethnic group. Do 
not rule out the possibility of this triggering clashes and friction in intercultural communication, which results in misunderstandings.

The parties conducting intercultural communication must have an honest and sincere desire to create a harmonious relationship (Fang and Faure 2011). This assumption requires a positive attitude from the actors of intercultural communication to eliminate superior-inferior relations based on membership of certain ethnic groups. Mutual understanding and understanding between each party must be created because treating others of different cultures in accordance with their desires can facilitate communication between them.

Each ethnic group has a superior feeling compared to other ethnic groups; the notion that the Chinese ethnic are foreigners who come and live in their territory continues to apply. The greater the differences between cultures, the greater the possibility of losing the opportunity to formulate a certain degree of effective communication. Strangers always try to reduce the level of uncertainty through proper forecasting of interpersonal relationships. Efforts to reduce uncertainty can be done through several stages, including pre-contact or the stage of impression formation through verbal and nonverbal symbols. Next, initial contact and impression, which is a further response to the impression that is generated or arisen from the first contact (Lewis and Weigert 1985). Finally, closure, begins to open up through attribution and personality development.

Interaction between indigenous Moslem and Chinese ethnic is still influenced by past history, Chinese ethnic prefer to deal with white people than indigenous Moslem. The problem of religion in Indonesia today is still influenced by what happened during the Dutch Colonial period. The division of citizen groups, the existence of different schools, which is compounded by the view that Islam is an indigenous religion, has given rise to a certain mind set, those at the top still feel at the top and look at other groups below.

In this study, researchers looked at from the perspective of Symbolic Interacted Theory to see social norms on interaction in indigenous Moslem and Chinese ethnic communities in Medan, then translated into Islamic symbols and the result was a difference in symbols where the symbols they used were contrary to Islam. The Chinese ethnic symbol is fire, in Islamic teachings fire is identical to jinn and devils.

\section{b. Interaction between Indigenous Moslem and Arabic Ethnic (A Comparative Case)}

Historically, the interaction of indigenous Moslem with other ethnicities such as the Arabs has been going on for a long time. Unlike the Chinese ethnic, the existence of the Arab ethnic is more welcomed by indigenous Moslem, because they are more able to mingle and assimilate with indigenous Moslem as indigenous people even though during the Dutch colonial period there was a clustering of various ethnic groups, but after the end of the colonial period they could be united with local residents. History records the role of the colonial government in the rules applied to various ethnicities in Indonesia, including the Arabs.

Coatings of the community can also be seen from the type of work. The Dutch and Europeans controlled important economies as owners of companies, industries, plantations and capital owners. They also master professional fields in government, lawyers, architects and many other professional professions. As for the Easterners, especially Arabs, most of the intermediary traders, moneylenders, laborers and other free workers. And only those who have a modern education can get decent jobs, such as government office employees and professional jobs. 
The purpose of the implementation of this policy is generally to separate the Arabs from the indigenous and put them in a kind of ghetto (a racial settlement center). Following up from the monitoring and grouping of settlements, an Arab captain was appointed who was responsible for the survival of the escort against the Arabs in his area. In terms of education, the Dutch government separates educational facilities for each ethnicity. In addition, they consider a person's social status to be accepted into school. These rules are strictly enforced, especially for indigenous.

The people of Indonesia welcomed the arrival of the Arabs to Indonesia; even they can read Arabic more than Latin. Thus, currencies in the Dutch period were written in Malay Arabic letters, Arabic Pegon or Arabic Jawi. In fact, at that time, romance stories including Chinese author writings were also written in Malay Arabic letters. The Arabs' belief in Islam was able to gain sympathy from the native people, and as privilege, they were allowed to marry offspring from local authorities and their status was equalized as a local people.

People of Arab descent settled in various locations in the city of Medan, they no longer grouped in one particular area, most of them residing scattered like other ethnic groups. From the work side, people of Arab descent already have a profession like indigenous people. From the side of the name is also difficult to distinguish because it is integrated with the indigenous Muslim community. The language used in daily life is Indonesian. The house and the atmosphere of their settlement are no different from the houses of Moslem communities in general.

Interaction between ethnic Arabs and indigenous Moslem is now very well established, so that social life and intercultural communication work in harmony. Although traces of the existence of ethnic Arabs still exist such as mosques, cemeteries and others, this has a positive influence and does not become a barrier in communication between native Moslem and Arab ethnic groups in the city of Medan.

\section{c. Interaction between Indigenous Moslem and India Ethnic (A Comparative Case)}

Another interaction is the interaction between indigenous Moslem and Indian ethnic groups that historically has been going on for a long time starting with the famous city of Medan as a het of dollar land in the world, resulting in traders, investors, immigrants and businessmen trying economic fortune in Medan in the early 20th century. Indians are brought in by large numbers of plantation entrepreneurs to be employed as plantation laborers. Since the opening of the first plantation, hundreds of Indians have been employed as plantation laborers. In line with the development of the plantation industry in East Sumatra, the number of Indian coolies employed as coolies has increased. In 1874 the number of new Indian coolies ranged from 459 people, in 1881 their population increased to 1,071 people, by 1890 there were 2,461 people and by 1990 it had reached 3,295 people.

Interaction with indigenous Moslem is characterized by marriage with indigenous Moslem women in the city of Medan. This is a form of social interaction and their adaptation to survive in the city of Medan. In addition, they also took an indigenous child to help their work as their servants in exchange for a small salary. Chetti people are known to be good at arithmetic so that the skill of arithmetic connects them to business relations with Arabs and Chinese who at that time held a strong economic position in Medan.

There is a side difference between ethnic Chinese and Indian descendants in Medan City, Chinese ethnic still use ancestral languages until the current generation, while Indian education in Medan City, Indian languages and scripts are generally used by older generations. 
When communicating among ethnic Indians, the older generation generally uses Hindi, Punjabi, Malabar and Tamil. While the younger generation no longer uses ancestral language because it has been replaced with Indonesian, this is a picture that they have mingled with the indigenous population.

\subsection{Discussion}

Ethnic stereotypes and prejudices can arise because they have been embedded since childhood, starting from the family and the environment (Aronson, Fried, and Good 2002). So before getting to know a person from a particular ethnicity, they have evaluated the ethnic person personally negatively based on what he heard (Padilla and Perez 2003). Stereotypes and prejudices still color the intercultural communication of the two ethnic groups in the city of Medan. The solution is that each person must know others personally and not what people say, because everyone will judge based on experience and different points of view. Mistakes in communication can lead to ethnic conflict especially if it brings religious elements so that the problems caused become more complex. Religion is always used as an excuse to bring down one another, because the issue of religion is very sensitive.

The solution to avoid stereotypes and prejudices is also done by way of each ethnic willing to open up and learn about other cultures, if everyone knows, then each tries to understand it, if it already understands, then there will be real steps in solving this problem. For example the selection of residences and schools that blend with Indigenous Moslem.

Other efforts to reduce stereotypes and prejudices are also carried out through engineering in inter-group relationships, through socialization with families, schools and the environment, through social engineering, and through personal self-awareness. Stereotypes and prejudices are also influenced by history, politics, economics, and social structure, hence the need for a strong political will from the government to make efforts to reduce stereotypes and prejudices. Because only the government has the ability to carry out social engineering widely and forcefully, both in the political, economic and social fields.

Stereotypes can occur continuously and continue to this day through communication among the community, and can be passed down to the next generation, so the solution to this problem is not just to look at an ethnic group from one side and ignore the other side. It must be realized that each individual from each ethnicity is born with its own uniqueness so that it does not need to be equated with other individuals.

Prejudice arises due to the lack of intercultural understanding of society (Ogbu 1992). Intercultural understanding is the cornerstone of a healthy multiethnic society, where each individual from both ethnic groups must be aware of differences and respect those differences. Intercultural understanding is one's ability to understand differences and be aware of cultural differences, and be able to accept differences (Winkelman 1994)(King and Baxter Magolda 2005). In essence reducing prejudice is tantamount to fostering understanding between ethnic. Fostering intercultural understanding and efforts to reduce other prejudices, can be done in all aspects of life, starting from the family, neighborhoods, schools, organizations and the wider community (Amin 2002).

Efforts to reduce prejudice can be done in many ways. Members of different ethnic groups can interact with each other; this will reduce a lot of prejudice between them and produce positive inter-group attitudes and stereotypes. The more and more closely the interactions that occur, the less stereotypes and negative prejudices will diminish (Fiske 1993)(Epstein 1994). 
The connection with this research is that in general each ethnic group has actually been formed for a long time, through a long period of time, interacting with each other, settling in one community together as the people of Medan City. However, stereotypes and prejudices are still found, causing social distance in interactions and an obstacle in communication and inhibiting social interaction between residents of Medan City. Forms of conflict that occur are latent (hidden) and open. In Medan, the current conflict is latent such as suspicion, negative prejudice and social jealousy. Most ethnic Chinese in Medan City have not been able to blend in with other ethnic groups, especially indigenous Moslem, they are still closed and segregated, and active participation in society is still low. The task of togetherness is always to replace / compensate with money, as a result the interaction cannot be established properly.

The majority of Medan residents are Moslem, so the attitude and outlook of Moslem towards pluralism is very important because it will have a significant impact on indigenous Moslem as a whole. When Moslem view pluralism as something positive, then that view will provide an important contribution to the realization of a life of communication that can bring mercy to all groups. Conversely, if Moslem view pluralism as negative, then that view has the potential to ignite conflict. In this context, it is very important, if a positive perspective on pluralism continues to be promoted among Moslem.

Interaction between members of the Islamic community and members of other communities is based on the principles of: (a) Good neighbors; (b) Mutual assistance in dealing with common enemies; (c) defend those who are persecuted; (d) Counseling one another; (e) respect for religious freedom. In the pattern of intercultural communication, it can be seen how people in the same ethnic group carry out the process of interpersonal exchange of thought (Amin 2002). Communication can be interpreted with symbols and language as concepts that can develop human thought patterns, ways of life, knowledge and ways of life that are expressed orally and in writing.

The people who inhabit Medan City are a plural society consisting of various ethnicities, such as Malays as native inhabitants of Medan City, and migrants such as the Minangkabau, Javanese, Sundanese, Batak, Bugis, Banjar, Ambonese, and descendants of Chinese, Arabic and Indian. In addition to inhabiting the Medan City area, they also live side by side and the integration process they experienced has been going on for a long time, since the time of the kingdom before the arrival of the western nations. The assimilation of each other has also been manifested in forms of culture that belong together.

Social norms reflect the characteristics that live in a society and are implemented as a means of conscious supervision by the community of its members. Considering the various prevailing social norms in the city of Medan, it is possible to have a conflict of values, in the sense of habits and customs which are considered good for one ethnic group, considered not well by other ethnic groups and vice versa.

Every communication process always experiences obstacles that affect the effectiveness of communication. In every communication wants communication can achieve the goal. In inter-cultural communication between indigenous Moslem and Chinese ethnic in Medan city, obstacles were still found including: 
a. Psychological Barriers

Communication barriers, which are included in psychological barriers, include stereotypes and prejudices, referred to as psychological barriers because they are elements of human psychic activity

b. Socio-cultural Barriers

Tens of thousands of islands stretching from Sabang (West Indonesia) to Merauke (East Indonesia) are Indonesia's priceless natural resources. Each island is inhabited by different ethnic groups, both native and immigrant. Large islands, such as Java, Sumatra, Sulawesi, Kalimantan, Papua, are divided into several parts, where each part has a different culture. Barriers included in socio-cultural barriers include various ethnicities, differences in social norms and language.

c. Barriers to Verbal Interaction

Barriers to verbal interaction include polarization and essential orientation. Polarization tendency to see the world in the form of opposite words and describe it in extreme forms, such as good or bad, positive or negative, healthy or sick, smart or stupid, and others. Intentional orientation refers to the tendency to see humans, objects and events in accordance with the characteristics inherent in them. Intentional orientation occurs when acting as if the label is more important than the person himself.

In this study, Psychological barriers are the main barriers in communication between indigenous Moslem and Chinese ethnic cultures in Medan. Communication is a process in which an interaction between the communicant and the communicator that exchanges messages in it that occurs directly or indirectly, communication itself can be said to mean nothing if the communication in it does not work properly, obstacles in communication within it do not work supposedly, because communication includes parties that act as senders and recipients alternately, these obstacles can occur from all parties.

There are several factors that hamper inter-cultural communication, between indigenous Moslem and Chinese ethnic in Medan City: firstly stereotyping and prejudice against indigenous Moslem who are lazy, ignorant and cannot use good opportunities, secondly; there was no change in the pattern of Chinese ethnic culture into the pattern of indigenous Moslem cults, or the strong in-group feeling of Chinese ethnic toward their culture. Third; the assumption of Chinese ethnic culture is higher than indigenous Moslem. On the contrary, stereotypes as indigenous Moslem against Chinese ethnic also emerge, such as Chinese ethnic referred to as groups who want to profit themselves without looking at halal or haram, discrimination especially on indigenous Moslem against Chinese ethnic in the opportunity to occupy the ranks of village / government officials, as well as values and strength open and latent conflicts as indicated by religious differences and economic disparity between the two ethnic groups. Chinese ethnic has some inherent stereotypes in which the indigenous population, such as cheating, stingy, suspicious, dirty, diligent, and loyal to their families. The emergence of ethnic stereotypes and prejudices as obstacles in communication because there is no mutual trust with each other, consequently each ethnic group always thinks that other ethnicities are bad and they are the best. However, negative views on certain ethnicities result in social distance and sluggish intermingling, which hinders the integration of society, especially in Medan City and the Indonesian people in general. 


\section{Conclusion}

Heterogeneous culture in the city of Medan, if not managed properly and in the right direction of polarization, it will cause social disintegration. All people or ethnic groups will make their groups socially and culturally dominant groups such as in the fields of economy, art, culture, politics and organization regardless of the existence of other groups, this difference, if managed properly, will be the main power in the development of this heterogenic civilization. An attitude of tolerance, respect, and joint responsibility for solving social problems that occur is very necessary.

Medan city is also known as a miniature of Indonesia. The population consists of various ethnicities; this must be made a cultural pride. Stereotypes and prejudices can be eliminated starting from the family, social environment, education by including multicultural education in the Indonesian curriculum, so that it can direct students and students to be tolerant and inclusive towards the reality of life amidst ethnic diversity, localism in multicultural education is the most important part. Because everyone can see themselves by understanding other ethnic cultures and can see diversity (other). So that each ethnic group can respect each other and eliminate the ethnic superiority ego.

\section{References}

Amin, Ash. (2002). "Ethnicity and the Multicultural City: Living with Diversity." Environment and Planning A 34(6): 959-80.

Aronson, Joshua, Carrie B. Fried, and Catherine Good. (2002). "Reducing the Effects of Stereotype Threat on African American College Students by Shaping Theories of Intelligence." Journal of Experimental Social Psychology 38(2): 113-25.

Bandura, Albert. (2001). "Social Cognitive Theory of Mass Communication." Media Psychology 3(3): 265-99.

Baron, R.A., and D. Byrne. (1987). Social Psychology: Understanding Human Interaction. 5th ed. MA, US: Needham Heights, MA, US: Allyn \& Bacon.

Batubara, M., U. et al. (2019). Islamic Communication Pattern of Judges in Dealing Conflict of Muslim Families in the Religious Court Medan. Budapest International Research and Critics Institute-Journal (BIRCI-Journal). P. 373-386.

Bhagat, Rabi S., Ben L. Kedia, Paula D. Harveston, and Harry C. Triandis. (2002). "Cultural Variations in the Cross-Border Transfer of Organizational Knowledge: An Integrative Framework." Academy of Management Review 27(2): 204-21.

Bodenhausen, Galen V, Geoffrey P Kramer, and Karin Siisser. (1994). "Attitudes and Social Cognition Happiness and Stereotypic Thinking in Social Judgment." Journal of Personality and Social Psychology 66(4): 621-32.

Connaughton, Stacey L., and Marissa Shuffler. (2007). Multinational and Multicultural Distributed Teams: A Review and Future Agenda. Small Group Research 38(3): 387-412.

Crandall, Christian S., Amy Eshleman, and Laurie O'Brien. (2002). "Social Norms and the Expression and Suppression of Prejudice: The Struggle for Internalization." Journal of Personality and Social Psychology 82(3): 359-77.

Epstein, Seymour. (1994). "Integration of the Cognitive and the Psychodynamic Unconscious." American Psychologist 49(8): 709-24.

Fang, Tony, and Guy Olivier Faure. (2011). "Chinese Communication Characteristics: A Yin Yang Perspective.” International Journal of Intercultural Relations 35(3): 320-33.

Fiese, Barbara H., Kimberly P. Foley, and Mary Spagnola. (2006). "Routine and Ritual Elements in Family Mealtimes: Contexts for Child Well- Being and Family Identity." In New Directions for Child and Adolescent Development, Wiley Periodicals, Inc. 
Fiske, Susan T. (1993). "Controlling Other People : The Impact of Power on Stereotyping." American Psychologist 48(6): 621-28.

Geertz, Clifford. (1973). "The Impact of the Concept of Culture on the Concept of Man.” In The Interpretation of Cultures, New York: Basic Books, Inc, 1-15.

Greenwald, Anthony G, and Mahrazin R Banaji. (1995). "Implicit Social Cognition: Attitudes, Self-Esteem, and Stereotypes." Psychological Review 102(1): 4-27.

Guyll, Max, Stephanie Madon, Loreto Prieto, and Kyle C. Scherr. (2010). "The Potential Roles of Self-Fulfilling Prophecies, Stigma Consciousness, An...: Discovery Service for FRESNO PACIFIC UNIV." Journal of Social Issues 66(1): 113-30. http://0eds.a.ebscohost.com.librarycatalog.fresno.edu/eds/pdfviewer/pdfviewer?vid=1\&sid= b1b61b35-5581-44c7-8ce4-7c209c416f87\%40sessionmgr4006.

Hilton, James L, and William Von Hippel. (1996). "STEREOTYPES."

Jost, John T., and Mahzarin R. Banaji. (1994). "The Role of Stereotyping in System-justification and the Production of False Consciousness." British Journal of Social Psychology 33(1): 1-27.

Kim, Young Yun. (2001). "Social Communication.” In Becoming Intercultural: An Integrative Theory of Communication and Cross-Cultural Adaptation, Thousand Oaks: SAGE Publications, Inc., 121-46.

King, Patricia M., and Marcia B. Baxter Magolda. (2005). "A Developmental Model of Intercultural Maturity.” Journal of College Student Development 46(6): 571-92.

Kunda, Ziva, and Steven J. Spencer. (2003). "When Do Stereotypes Come to Mind and When Do They Color Judgment? A Goal-Based Theoretical Framework for Stereotype Activation and Application." Psychological Bulletin 129(4): 522-44.

Lewis, J. David, and Andrew Weigert. (1985). "Trust as a Social Reality." Social Forces 63(4): 967-85.

Mannix, Elizabeth, and Margaret A Neale. (2005). "What Differences Make a Difference?: The Promise and Reality of Diverse Teams in Organizations." Psychological Science in the Public Interest 6(2): 31-55.

Nagda, Biren A. (2006). "Breaking Barriers, Crossing Borders, Building Bridges: Communication Processes in Intergroup Dialogues.” Journal of Social Issues 62(3): 553-76.

Neuner, Gerhard, and Katarzyna Karwacka-Vögele. (2012). Intercultural competence for all: Preparation for living in a heterogeneous world Chapter One: Towards a Framework for Intercultural Education.

Ogbu, John U. (1992). "Understanding Cultural Diversity and Learning." Educational Researcher 21(8): 5-14.

Padilla, Amado M., and William Perez. (2003). "Acculturation, Social Identity, and Social Cognition: A New Perspective.” Hispanic Journal of Behavioral Sciences 25(1): 35-55.

Pettigrew, Thomas F. (1997). "Generalaized Intergroup Contact Effect on Prejudice." PSPB 23(2): 173-85.

PG, Devine. (1989). "Stereotypes and Prejudice: Their Automatic and Controlled Components." Journal of Personality and Social Psychology 56(1): 5.

Rafaeli, Sheizaf. "From New Media to Communication.” In Interactivity, , 110-34.

Spencer-Rodgers, Julie, and Timothy McGovern. (2002). "Attitudes toward the Culturally Different: The Role of Intercultural Communication Barriers, Affective Responses, Consensual Stereotypes, and Perceived Threat." International Journal of Intercultural Relations 26(6): 609-31.

Ting-Toomey, Stella. (1984). "Intercultural Communication Theory: Current Perspectives." International Journal of Intercultural Relations 8(2): 228-31.

Winkelman, Michael. (1994). "Cultural Shock and Adaptation." Journal of Counseling \& Development 73: 121-26. 